BMJ Paediatrics Open

\title{
Addressing inequities in child health and development: towards social justice
}

\author{
Nick Spencer, ${ }^{\oplus 1}$ Shanti Raman, ${ }^{2,3}$ Bernadette O'Hare, ${ }^{4,5}$ Giorgio Tamburlini ${ }^{6}$
}

To cite: Spencer N, Raman S, O'Hare B, et al. Addressing inequities in child health and development: towards social justice. BMJ Paediatrics Open 2019;3:e000503. doi:10.1136/ bmjpo-2019-000503

Received 10 April 2019

Revised 18 July 2019

Accepted 22 July 2019
Check for updates

(c) Author(s) (or their employer(s)) 2019. Re-use permitted under CC BY-NC. No commercial re-use. See rights and permissions. Published by BMJ.

'Division of Mental Health and Wellbeing, University of Warwick Warwick Medical School, Coventry, UK

${ }^{2}$ Department of Community Paediatrics, South Western Sydney Local Health District, Liverpool, New South Wales, Australia

${ }^{3}$ Women's \& Children's Health, University of New South Wales, Sydney, New South Wales, Australia

${ }^{4}$ School of Medicine, University of Saint Andrews, Saint Andrews, UK

${ }^{5}$ College of Medicine, University of Malawi, Zomba, Malawi

${ }^{6}$ Centro per la Salute del Bambino Onlus, Trieste, Italy

Correspondence to Dr Nick Spencer; N.J.Spencer@ warwick.ac.uk

\section{ABSTRACT}

Inequities have a profound impact on the health and development of children globally. While inequities are greatest in the world's poorest countries, even in rich nations poorer children have poorer health and developmental outcomes. From birth through childhood to adolescence, morbidity, mortality, growth and development are socially determined, resulting in the most disadvantaged having the highest risk of poor health outcomes. Inequities in childhood impact across the life course. We consider four categories of actions to promote equity: strengthening individuals, strengthening communities, improving living and working conditions, and promoting healthy macropolicies. Inequities can be reduced but action to reduce inequities requires political will. The International Society for Social Paediatrics and Child Health (ISSOP) calls on governments, policy makers, paediatricians and professionals working with children and their organisations to act to reduce child health inequity as a priority. ISSOP recommends the following: governments act to reduce child poverty; ensure rights of all children to healthcare, education and welfare are protected; basic health determinants such as adequate nutrition, clean water and sanitation are available to all children. Paediatric and child health organisations ensure that their members are informed of the impact of inequities on children's well-being and across the life course; include child health inequities in curricula for professionals in training; publish policy statements relevant to their country on child health inequities; advocate for evidence-based pro-equity interventions using a child rights perspective; advocate for affordable, accessible and quality healthcare for all children; promote research to monitor inequity as well as results of interventions in their child populations. Paediatricians and child health professionals be aware of the impact of social determinants of health on children under their care; ensure their clinical services are accessible and acceptable to all children and families within the constraints of their country's health services; engage in advocacy at community and national level.

\section{INTRODUCTION}

'Social justice is a matter of life and death'. This statement in the WHO Commission on Social Determinants of Health report ${ }^{1}$ captures the essence of health inequities that have a profound effect on the health of populations across the world. Children are especially vulnerable to the impact of social disadvantage and inequities, which are evident from birth and have a profound effect on health across the life course. ${ }^{2}$ The WHO report has the subtitle 'Closing the Gap in a generation' reflecting the conviction that inequities can be eliminated. This short version of the International Society for Social Paediatrics and Child Health (ISSOP) Position Statement ${ }^{3}$ contributes to the promotion of child health equity by identifying the nature and extent of child health inequities, interventions that work and actions by paediatricians and professionals working with children, their national and international societies and governments needed to achieve equity.

\section{Statement of the problem}

We use the term health inequities to denote those health inequalities that are avoidable and relate to the social circumstances in which children are conceived, born, live, develop and grow. Inequities are unjust. ${ }^{4}$ Child health equity means that every child has a fair and just opportunity to be as healthy as possible.

The social and economic determinants are the underlying factors shaping children's health and life chances in all countries. These determinants of health are hierarchical: individual outcomes are shaped by living and working conditions at the household and in the community, which are shaped by decisions made by public bodies and the local government. Local government capacity and actions are in turn shaped by decisions made at national level, including how much revenue and decision-making power is kept centrally and how much is decentralised. National level revenue and policy space is influenced by macro decisions made at the global level such as the conditions attached to a loan or aid. This results in a complex web of direct and indirect causality, leading to differential exposure to risk and protective factors resulting in maintenance and generation of inequities.

Inequities in child health outcomes occur between and within countries. Child health outcomes show huge inequities between low-income (LICs), middle-income (MICs) and high-income countries (HICs). Table 1 


\begin{tabular}{|c|c|}
\hline Region & U5MR ( $90 \%$ uncertainty bounds) \\
\hline Sub-Saharan Africa & $83.1(77.5,93.0)$ \\
\hline All developing countries & $46.5(44.7,50.0)$ \\
\hline World & $42.5(40.9,45.6)$ \\
\hline All developed countries & $5.8(5.5,6.3)$ \\
\hline
\end{tabular}

U5MRs, under-5 mortality rates.

shows the extent of the gap in under-5 mortality rates (U5MRs) between countries grouped by region and level of development. $^{2}$

While child mortality rates have decreased significantly over the last few decades, the differences in child survival shown in table 1 highlight the continuing loss of children's lives due to the social, political and environmental circumstances in which they are born and grow. ${ }^{1}$

Within country inequities in child survival rates are marked in both lower middle-income countries (LMICs) and HICs. In all countries, children in low-income families have higher rates of infant mortality rate and U5MR than those in high-income families. ${ }^{5-7}$ Compared with those in the richest fifth of households in LMICs, children in the poorest fifth are twice as likely to die before aged 5 and children in HICs with high rates of child poverty are at increased risk of dying before the age of 5 years. ${ }^{5}$

Low birth weight (LBW) is the most important risk factor for death in infancy and early childhood, with long-term consequences on mortality and ill health into adult life. The incidence of LBW is around $15.5 \%$ globally (ie, more than 20 million infants worldwide), $16.5 \%$ in LMICs and up to $27 \%$ in South-East Asia, while it is around $6 \%$ in Western Europe. Estimates of preterm births vary around an average of $11.3 \%$ of all births (up to $18 \%$ in some African countries), corresponding to approximately 13 million/year. Out of these, at least 10.9 million are born in Africa or Asia.

Inequity in LBW has been consistently reported in HICs. ${ }^{8}$ Higher rates of U5MR in England compared with Sweden are largely explained by higher rates of preterm birth and LBW. ${ }^{9}$

Moderate to severe stunting $(>2 \mathrm{SD}$ below median height-for-age of the WHO Child Growth Standards) among children $<5$ years of age shows a similar pattern of global inequity; stunting affects $37 \%$ of children in the least developed countries, $11 \%$ in the MICs of East Asia and the Pacific, and Latin America and the Caribbean compared with little recorded stunting in HICs. ${ }^{2}$ Across LMICs, children in the poorest $20 \%$ are over twice as likely to be stunted as those in the richest $20 \%$. $^{2}$

Children in low-income families in HICs are at increased risk of adverse health outcomes throughout childhood and adolescence. Systematic literature reviews report higher risk of LBW, preterm birth, infant mortality, developmental difficulties and disorders, acute and chronic respiratory conditions ${ }^{10}$ and disabling chronic conditions ${ }^{11}$ among children in low-income households compared with their more advantaged peers in HICs. Overweight and obesity are more prevalent among the children of mothers with low levels of education. ${ }^{12}$

Violence is a global public health issue linked with inequities. Both intentional or inflicted violence and unintentional injuries are associated with child poverty. The burden from child injury is greatest in LMICs, where $95 \%$ of all child-injury deaths occur, and where recorded rates of child maltreatment are higher than in HICs. ${ }^{13}$ Structural violence, violence exerted indirectly through social structures characterised by poverty and social inequality, generates and perpetuates inequities, particularly for children and young people in LMICs. ${ }^{14}$

\section{Inequity in access to the determinants of health}

The determinants that are critical for health outcomes include clean air, water, sanitation, shelter and nutrition. Household air pollution causes $50 \%$ of lower respiratory tract infections which is responsible for $15 \%$ of deaths in children. Inadequate water and sanitation are responsible for more than half of the disease burden due to diarrhoea, which is responsible for $10 \%$ of under-five mortality, while environmental interventions could halve the disease burden due to malaria. ${ }^{15}$

These social determinants of health (SDH) are core human rights, enshrined in the Universal Declaration of Human rights and the United Nations Convention on the Rights of the Child (UNCRC). ${ }^{16}$ The indicators, which will be used in the Sustainable Development Goal era, ${ }^{17}$ include these and all children in all countries should have immediate access. Access to these determinants is unequal, the poorest children being far more likely to be deprived despite some improvement in coverage over recent decades. ${ }^{18}$

\section{Inequity in child health services}

Inequity in child health services is a major determinant of child health inequity. The majority of conditions responsible for mortality and morbidity among children in LMICs are preventable and treatable but limited access and affordability continue to deny poor children essential treatment. Lack of medical insurance in some HICs also excludes many poor children from access to essential treatment. Figure 1 shows inequity by wealth index for interventions of proven efficacy in 54 LMICs. $^{19}$

\section{Early child development: a critical determinant for equity}

Most health and social inequities originate in the earliest periods of life and even before, since transmission of a significant proportion of inequities is intergenerational..$^{20}$ The earliest periods of life are crucial for the development of most systems and organs and primarily for the brain, thus establishing the biological foundations for lifelong functioning. ${ }^{21}$ In the earliest years there is a window of both vulnerability and opportunity that is the most important along the entire life span. 


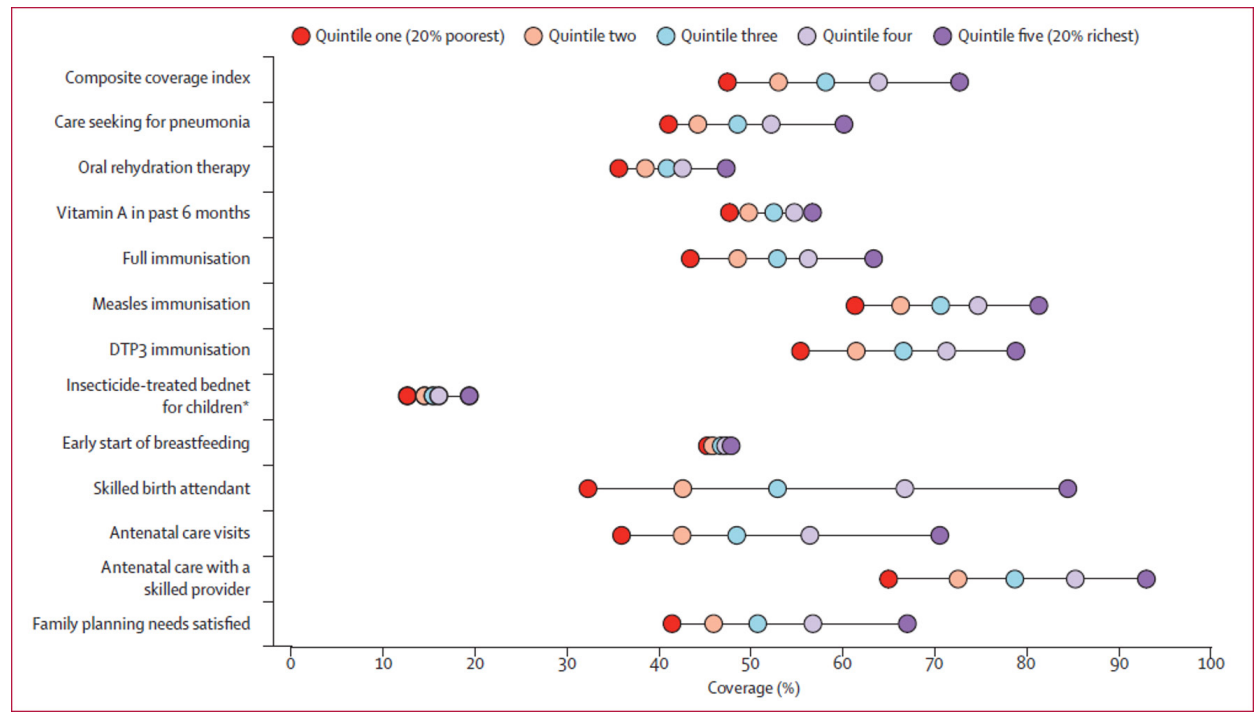

Figure 1 Mean coverage for each wealth quintile for interventions in 52 countdown countries. Source: Barros et al. ${ }^{19}$ (Reproduced with permission from Elsevier (License number 4593591509657).)

The development of neural networks and the entire brain architecture is shaped by the early environment: the thickness of brain cortex and the size of important underlying functional hubs such as the hippocampus are associated with family income, parental education, parenting styles and adverse life experiences. ${ }^{22}{ }^{23}$ Child development is influenced by a range of factors from socioeconomic background to the psychosocial and physical environment including family income, parental stress, maternal education, breast feeding and nutrition, parent-child interactions and parental skills, day care attendance and environmental exposure. ${ }^{24}$ From very early in life, and particularly since conception and up to the third year, risk and protective factors combine to determine different trajectories in child development, ranging from very delayed to optimal, which will continue to produce their effects throughout the life course. ${ }^{24}$

\section{The pervasive effect of social and economic inequity on society}

High levels of social and economic inequity act as a social stressor, disturbing the social cohesion and damaging the social fabric, so important for a healthy society. ${ }^{25-27}$ For example, parental stress increases the risk of unfavourable neonatal outcomes, maltreatment and later behavioural and mental problems. ${ }^{28}{ }^{29}$ Greater equity makes most difference to the least well off but also produces benefits for the well off, by facilitating the sense of balance and control in life and increasing the generalised trust, ${ }^{25} 30$ ultimately benefitting the whole society.

\section{Policies and interventions that work}

While recognising the importance of international policy interventions in responding to within-country inequity, this section focuses mainly on within-country policy to promote child health equity.

Whitehead ${ }^{31}$ identified four categories of actions to tackle health inequities: (1) strengthening individuals; (2) strengthening communities; (3) improving living and working conditions; (4) promoting healthy macro-policies. All categories require political will, government-level investment and support. To be effective, actions in all categories need to reach the poorest. New data and analysis show that the number of lives saved per million dollars invested among the poorest children is almost twice as high as the number saved by equivalent investments in less deprived groups. ${ }^{32}$

\section{Strengthening individuals and communities}

In LMICs, evidence-based interventions aimed at addressing maternal and child undernutrition, a major determinant of inequity, can be delivered through community engagement and pro-poor delivery strategies that reach poor segments of the population at greatest risk. ${ }^{33} 34$ These include-periconceptional folic acid supplementation or fortification, maternal and infant balanced energy protein supplementation, micronutrient supplementation in pregnancy, promotion of breast feeding, appropriate complementary feeding, vitamin $\mathrm{A}$ and preventive zinc supplementation in children 6-59 months of age, clinical management of acute malnutrition. Interventions aimed at enhancing horizontal social interactions, particularly those targeting women's groups practising participatory learning and action, have a strong evidence-base in low resource settings. ${ }^{35}$

Effective interventions in LMICs and HICs to promote early child development should include direct learning experiences to children and families, target younger and disadvantaged children, be long-term, high quality and high intensity, and integrated with family support, health, nutrition, educational services, welfare and finance sectors. ${ }^{336}$ Universal access to early promotion and assessment of child development since birth are key to equitable outcomes. Early education programmes enhance early childhood development among disadvantaged 
children and impact health and well-being across the life course in both HICs and LMICs. ${ }^{37-39}$

The 'Three Generation Approach' is designed to break the cycle of intergenerational disadvantage. ${ }^{20}$ This approach emphasises childhood, adolescence and young adulthood as critical period during which the health, social/welfare and education sectors must work together in optimising (1) young people's capacities for education, employment, productivity; (2) preconception health; (3) reproductive life course planning and (4) parenting capacities.

\section{Improving living and working conditions and promoting healthy macroeconomic policies}

In LMICs women's empowerment, agriculture, food systems, education, employment, social protection and safety nets are essential to ensure adequate levels of nutrition in child populations. ${ }^{33}$ A living wage and healthcare system financing providing prepayment system (funded either through progressive income tax or universal social insurance) are essential to protect against catastrophic out-of-pocket health spending. ${ }^{40}$

Investment in early education for disadvantaged children from birth to age 5 helps reduce the achievement gap, reduce the need for special education, increase the likelihood of healthier lifestyles, lower the crime rate and reduce overall social costs. ${ }^{3740}$ Policies that provide early childhood educational resources to the most disadvantaged children produce greater social and economic equity. ${ }^{41}$

To achieve child health equity, access to effective healthcare services is essential. Universal health coverage (UHC) means all people receiving the health services they need, including health promotion, illness prevention (such as vaccinations), and treatment, rehabilitation and palliative care of sufficient quality to be effective while ensuring that the service user is not exposed to financial hardship. ${ }^{39}$

An estimated 400 million people do not receive healthcare consistent with this definition. Policy approaches differ across LMICs ${ }^{40}$ : some, such as Costa Rica, Brazil and Cuba, have succeeded in ensuring affordable and effective UHC despite relatively limited resources. Case studies in Africa, Asia and Latin America of reaching the poor with health, nutrition and population programme show that better performance in reaching the poor is both needed and feasible. ${ }^{34}$ Poor and marginalised people face barriers in access to, affordability of, and use of health interventions and services ${ }^{364243}$ which, if not addressed, will lead to increasing inequity (see box 1).

Investments that increase access to high-impact health and nutrition interventions by poor groups have saved almost twice as many lives as equivalent investments in non-poor groups. ${ }^{32}$ The key practical, high-impact and low-cost health interventions include insecticide-treated nets to prevent malaria; oral rehydration salts to treat diarrhoea; early immunisation against vaccine-preventable diseases; primary and community-based health
Box 1 Barriers to healthcare faced by poor and marginalised ${ }^{36}$

\section{Accessibility}

Physical access to health services is frequently difficult for people in remote rural areas with limited transport infrastructure and infrequent outreach services and contact with trained health professionals.

\section{Affordability}

Out-of-pocket payments at the point of use of health services deter the poor and marginalised in LMICs and in some HICs.

\section{Acceptability}

Health services which do not take account of cultural and religious sensitivities are a barrier to use especially by women in poorer communities.

\section{Utilisation}

Cultural and religious norms may prevent people, and particularly women, from using available services.

\section{Quality and continuity of care}

For an intervention to be fully effective-for example, children receiving treatment for a chronic disease or a course of vaccinations-quality and continuity across time and services must be ensured, which is frequently not the case for those most in need.

HICs, high-income countries; LMICs, low and middle-income countries.

services such as skilled birth attendants to reduce complications during labour and delivery; early initiation of breast feeding continuing for the first 6 months of life; and care-seeking by parents of young children to treat illness. Community-based interventions are more equally distributed than those delivered in health facilities. ${ }^{19}$

National and international economic and social policies are important determinants of inequities. National income (Gross Domestic Product/capita) is an important determinant of child survival ${ }^{44}$ and, along with the level of governance, it determines how well a country can provide for their citizens with the essential social determinants of health (SDH) ${ }^{45}$ Stopping leaks from government revenue, including tax avoidance by domestic companies, multinational companies and wealthy residents and tax incentives which do not promote economic growth, is essential if LMICs are to retain resources necessary to reduce poverty. ${ }^{46}$ International and local action to end wars, use of scarce resources to buy armaments ${ }^{47}$ and debt repayment, all of which are promoted by HICs, can contribute to ending these drains on essential government revenue.

Growth alone without pro-poor policies may improve child survival overall but increase inequity. ${ }^{45}$ Pro-poor policies introduced by governments reduce inequity in child health in LMICs. Conditional Cash Transfer programmes have been shown to have wide-ranging positive effects. ${ }^{48-54}$ There is also evidence of shortterm to medium-term impact on poor households with evidence of reduction in inequity in uptake of preventive child health services including immunisation ${ }^{55}$ and, in the longer term, sustained improvement in education 
and achievement among poor boys stretching into early adulthood. ${ }^{56}$

HICs, which adopt social and economic policies that reduce child poverty rates, reduce income and wealth inequalities and protect families and children from risk, ${ }^{57}$ have reduced levels of child health inequities.

\section{Recommendations}

Reducing child health inequities is the great moral/ ethical test of our time. ISSOP therefore recommends the following at different levels.

\section{For governments}

1. Recognise child poverty is detrimental to health and well-being across the life course and act to reduce child poverty rates.

2. Continue with or urgently enact policies designed to reduce inequities in child health and development in line with WHO recommendations. ${ }^{1}$

3. Commit to implementing Sustainable Development Goals (SDG) Poverty targets including:

a. Diminishing poverty by $50 \%$ by 2030 .

b. Implementing appropriate social protection systems for the poor.

c. Ensuring equal access to economic resources.

d. Mobilising resources for the poor.

4. Recognise that health inequity violates children's rights under the UNCRC and ensure the rights of all children are fully protected.

5. Ensure the basic determinants of health such as adequate nutrition, education, clean water and sanitation are available to all children.

Using a simple schema proposed by The College of Family Physicians of Canada, ${ }^{58}$ paediatricians and professionals working with children can act at three levels:

1. Micro-in practice: At the individual level, clinicians can regularly assess to what extent children and their families are exposed to poverty and intervene where appropriate. Paediatricians can ensure their clinical services are accessible and acceptable to all children and families, especially marginalised populations. To address complex problems among vulnerable groups, flexibility of appointment times and duration is essential. Multidisciplinary and team-based models of care with access to social welfare services are necessary for marginalised populations.

2. Meso-in communities: Paediatricians can collect and use data on their local population's health and well-being; promote undergraduate and postgraduate experiential learning on the SDH; and engage in advocacy at a community level.

3. Macro-national and international: Paediatricians can form advocacy groups or networks to take a stance on poverty and its impact on children. Advocacy efforts should be directed at all levels of government and international organisations, such as the International Monetary Fund which has significant influence on domestic policy space. Paediatricians can engage with their own and other medical, healthcare and social service organisations to provide organisational advocacy to work on improving the SDH and use the framework and targets of the SDGs to prioritise their advocacy.

For national and international paediatric and child health professional organisations

1. Ensure their members and constituent bodies are aware of the impact of inequities on the health and well-being of children and across the life course.

2. Include global child health inequities in their national programmes and curricula for medical students and paediatricians in training.

3. Publish policy statements relevant to their country or regional setting highlighting the impact of inequities on child health and well-being.

4. Advocate for evidence-based pro-equity interventions with policy makers at national, regional or global level using a child rights perspective.

5. Promote and institute data collection and policy focused research to monitor inequity in child populations and study social policy responses and interventions that promote equity in child health and well-being.

6. Participate in global partnerships based on SDG targets and advocate, through these partnerships, for child health equity using a child health perspective.

Acknowledgements The following colleagues in the Inequity Working Group contributed references and suggestions to early drafts of the position statement: David Taylor-Robinson, Tony Waterston, Takonda Chimowa, Marion Drew, Hafsat Rufai Ahmad, Rosie Kyeremateng, Craig Nyathi and Isa Abdulkadir.

Funding The authors have not declared a specific grant for this research from any funding agency in the public, commercial or not-for-profit sectors.

Competing interests None declared.

Patient consent for publication Not required.

Provenance and peer review Commissioned; externally peer reviewed.

Data availability statement There are no data in this work.

Open access This is an open access article distributed in accordance with the Creative Commons Attribution Non Commercial (CC BY-NC 4.0) license, which permits others to distribute, remix, adapt, build upon this work non-commercially, and license their derivative works on different terms, provided the original work is properly cited, appropriate credit is given, any changes made indicated, and the use is non-commercial. See: http://creativecommons.org/licenses/by-nc/4.0/.

\section{REFERENCES}

1. WHO Commission on Social Determinants of Health. Closing the gap in a generation: health equity through action on the social determinants of health. Final Report of the Commission on Social Determinants of Health. Geneva: World Health Organization, 2008.

2. UNICEF. The State of the World's Children 2016: A Fair Chance for Every Child. New York: UNICEF, 2016.

3. International Society for social pediatrics and child health (ISSOP) position statement 1 on child health inequities - June 2018 update. Available: https://www.issop.org/cmdownloads/issopposition-statement-1-on-child-health-inequities-june-2018-update/ [Accessed 13 May 2019].

4. Whitehead M. The Concepts and Principles of Equity and Health. Copenhagen: World Health Organization Regional Office for Europe, 1990.

5. Taylor-Robinson D, Higgerson J, Anwar E, et al. A fairer start for children in the North of England. University of Liverpool, 2014.

6. UNICEF. Progress for children No.11. Beyond averages: learning from the MDGs. New York: UNICEF, 2015. 
7. Sidebotham P, Fraser J, Covington T, et al. Understanding why children die in high-income countries. Lancet 2014;384:915-27.

8. Spencer N. Weighing the evidence: how is birthweight determined? Oxford: Radcliffe Medical Press, 2003

9. Zylbersztejn A, Gilbert R, Hjern A, et al. Child mortality in England compared with Sweden: a birth cohort study. Lancet 2018;391:2008-18.

10. Pillas D, Marmot M, Naicker K, et al. Social inequalities in early childhood health and development: a European-wide systematic review. Pediatr Res 2014;76:418-24.

11. Spencer NJ, Blackburn CM, Read JM. Disabling chronic conditions in childhood and socioeconomic disadvantage: a systematic review and meta-analyses of observational studies. BMJ Open 2015;5:e007062.

12. Pikhart $\mathrm{H}$, Ruiz M, Morrison J, et al. Social inequalities in early childhood health and development: a European-wide systematic review. Drivers Working Party 2 ECD, 2014. Available: http://healthgradient.eu/wp-content/uploads/2015/03/DRIVERS_WP2_Early_ Child_Development_Final_Report.pdf [Accessed 2 Nov 2017].

13. Mock C, Peden M, Hyder AA. Child injuries and violence: the new challenge for child health. Bull World Health Organ 2008;2008:420.

14. Farmer P. An anthropology of structural violence. Curr Anthropol 2004:45:305-25.

15. WHO. Don't pollute my future! The impact of the environment on children's health. Geneva: World Health Organization, 2017. Available: http://www.who.int/ceh/publications/don-t-pollute-myfuture/en/ [Accessed 3 Nov 2017].

16. Pemberton S, Gordon D, Nandy S, et al. Child rights and child poverty: can the International framework of children's rights be used to improve child survival rates? PLoS Med 2007;4:e307-70.

17. O'Hare B, Devakumar D, Allen S. Using international human rights law to improve child health in low-income countries : a framework for healthcare professionals. BMC Int Health Hum Rights 2016;16.

18. WHO/UNICEF. WHO/UNICEF Joint Monitoring Programme for Water and Sanitation [WWW Document], 2016. Available: https://www. wssinfo.org/ [Accessed 4 Oct 2017].

19. Barros AJD, Ronsmans $\mathrm{C}$, Axelson $\mathrm{H}$, et al. Equity in maternal, newborn, and child health interventions in countdown to 2015: a retrospective review of survey data from 54 countries. Lancet 2012;379:1225-33.

20. Cheng TL, Johnson SB, Goodman E. Breaking the intergenerational cycle of disadvantage: the three generation approach. Pediatrics 2016;137:e20152467.

21. Shonkoff J. The science of child development. Center for the Developing Child, Harvard University, Mass, 2007.

22. Luby J, Belden A, Botteron K, et al. The effects of poverty on childhood brain development: the mediating effect of caregiving and stressful life events. JAMA Pediatr 2013;167:1135-42.

23. Jednoróg K, Altarelli I, Monzalvo K, et al. The influence of socioeconomic status on children's brain structure. PLoS One 2012;7:e42486.

24. Walker SP, Wachs TD, Grantham-McGregor S, et al. Inequality in early childhood: risk and protective factors for early child development. Lancet 2011;378:1325-38.

25. Marmot M. Status Syndrome: How your Place on the Social Gradient Directly Affects Your Health and Life Expectancy. London: Bloomsberry, 2004: 1. 150-4.

26. WHO. Financial Crisis and Global Health: Report of a High-Level Consultation. Geneva: World Health Organization, 2009.

27. Köhler L. Children's health in Europe - challenges for the next decades. Health Promot Int 2017:1-9.

28. WHO European Office. European report on preventing child maltreatment. Copenhagen: World Health Organization, European Office, 2013

29. Newman L, Judd F, Olsson CA, et al. Early origins of mental disorder - risk factors in the perinatal and infant period. BMC Psychiatry 2016;16:270.

30. Antonovsky A. Unravelling the mystery of health. How people manage stress and stay well. San Francisco: Josey-Bass, 1987.

31. Whitehead M. A typology of actions to tackle social inequalities in health. J Epidemiol Community Health 2007;61:473-8.

32. Tamagni J, Taylor G. Narrowing the Gaps: The power of investing in the poorest children. New York: United Nations Children's Fund (UNICEF), 2017

33. Bhutta ZA, Das JK, Walker N, et al. Interventions to address deaths from childhood pneumonia and diarrhoea equitably: what works and at what cost? Lancet 2013;381:1417-29.

34. Wagstaff A, Bustreo F, Bryce J, et al. Child health: reaching the poor. Am J Public Health 2004;94:726-36.
35. Prost A, Colbourn T, Seward N, et al. Women's groups practising participatory learning and action to improve maternal and newborn health in low-resource settings: a systematic review and metaanalysis. Lancet 2013;381:1736-46.

36. Chopra M, Sharkey A, Dalmiya N, et al. Strategies to improve health coverage and narrow the equity gap in child survival, health, and nutrition. Lancet 2012;380:1331-40.

37. Heckman JJ, Moon SH, Pinto R, et al. The rate of return to the HighScope Perry preschool program. J Public Econ 2010;94:114-28.

38. Welshman J. From head start to sure start: reflections on policy transfer. Children Society 2010;24:89-99.

39. Rao N, Sun J, Chen EE, et al. Effectiveness of early childhood interventions in promoting cognitive development in developing countries: a systematic review and meta-analysis. HK J Paediatr 2017:22:14-25.

40. WHO/WB. Tracking universal health coverage: 2017 global monitoring report. World Health Organization and International Bank for Reconstruction and Development / The World Bank, 2017. Available: http://www.who.int/healthinfo/universal_health_coverage/ report/2017/en/ [Accessed 24 May 2018]

41. Heckman JJ. The economics of inequality. The value of early education. American Educator 2011:35-47.

42. Victora CG, Joseph G, Silva ICM, et al. The inverse equity hypothesis: analyses of institutional deliveries in 286 national surveys. Am J Public Health 2018;108:464-71.

43. Victora CG, Vaughan JP, Barros FC, et al. Explaining trends in inequities: evidence from Brazilian child health studies. Lancet 2000;356:1093-8.

44. O'Hare B, Makuta I, Chiwaula L, et al. Income and child mortality in developing countries: a systematic review and meta-analysis. $J R$ Soc Med 2013;106:408-14.

45. Population Reference Bureau. Improving the health of the world's poorest people. Policy Briefing, Population Reference Bureau, Washington, 2004. Available: http://www.prb.org/pdf04/Improvin gtheHealthbrief_Eng.pdf [Accessed 24 Aug 2017].

46. O'Hare B, Makuta I. An analysis of the potential for achieving the fourth millennium development goal in SSA with domestic resources. Global Health 2015;11:8.

47. Grimmett RF, Kerr PK. Conventional Arms Transfers to Developing Nations, 2004-2011. Congressional Research Service, Washington DC, 2014. Available: https://fas.org/sgp/crs/weapons/R42678.pdf [Accessed 24 Aug 2017].

48. Paul Schultz T, Schultz TP. School subsidies for the poor: evaluating the Mexican Progresa poverty program. J Dev Econ 2004;74:199-250.

49. Bobonis G, Finan F. Endogenous social interaction effects in school participation in rural Mexico. Berkeley, CA: University of California, 2005.

50. Gertler P, Martinez S, Rubio M. Investing cash transfers to raise long term living standards. Berkeley, CA: University of California, 2005

51. Gertler P. Do conditional cash transfers improve child health? Evidence from PROGRESA's control randomized experiment. Am Econ Rev 2004:94:336-41.

52. Hoddinott J, Skoufias E. The impact of PROGRESA on food consumption. Econ Dev Cult Change 2004;53:37-61.

53. Coady D, Harris RI. Evaluating Transfer Programs Within a General Equilibrium Framework. FCND Discussion Paper, No. 110. Washington, DC: International Food Policy Research Institute, 2001.

54. Soares FV, Soares S, Medeiros M, et al. Cash Transfer Program in Brazil: Impact on Equality and Poverty. International Poverty Centre Working Paper, No. 21, June. Brasília, International Poverty Centre, 2006. Available: http://www.ipc-undp.org/pub/IPCWorkingPaper21. pdf [Accessed 2 May 2017].

55. Rawlings LB, Rubio GM. Evaluating the Impact of Conditional Cash Transfer Programs: Lessons from Latin America. World Bank Policy Research Working Paper 3119, 2003. Available: http://documents. worldbank.org/curated/en/873471468753288128/108508322 20041117165019/additional/multiOpage.pdf [Accessed 2 May 2017].

56. Barham T, Macours K, Maluccio JA. More Schooling and More Learning? Effects of a Three-Year Conditional Cash Transfer Program in Nicaragua after 10 Years. Inter-American Development Bank, 2013. Available: https://www.povertyactionlab.org/sites/default/files/ publications/578\%2010\%20year\%20follow\%20up\%20July2013.pdf [Accessed 2 May 2017].

57. UNICEF. Child Poverty in Rich Countries, 2005. Innocenti Report Card No.6. Florence: UNICEF Innocenti Research Centre, 2005.

58. Best Advice. Social determinants of health. Ontario, Canada: The College of Family Physicians of Canada, 2015. 